\title{
El financiamiento político en la región americana. Hacia un sistema que preserve la equidad y la transparencia electoral
}

\section{Ricardo González Dorfman}

"Para evitar que las decisiones de las autoridades respondan a intereses espurios y prevenir la corrupción es necesario contar con una buena regulación y un sistema de control eficiente.

Para que el financiamiento de la política no sea una puerta abierta a la compra de influencia, o incluso a la compra de cargos y funciones, es necesario terminar con la impunidad de los que violan la ley y con la indiferencia de la sociedad frente a los abusos" (Ferreira Rubio, 2012).

\section{Resumen}

El presente artículo conceptualiza el sentido fundamental y la función que tienen los partidos políticos y bucea las razones de su financiamiento, centralmente el de las campañas electorales. Desarrolla los objetivos y elementos constitutivos existentes (expresa o implícitamente) en todo sistema de financiamiento electoral, en su horizonte de preservar la integridad, transparencia y equidad electoral. Se relevan los distintos motivos que fundamentan tanto el financiamiento público como el privado, destacando los riesgos de cooptación de la representación institucional por intereses particulares e ilegales con motivo de tal transferencia de fondos. En la segunda parte se describen las características de los mecanismos de transparencia, rendición de cuentas y fiscalización, profundizando el análisis de las herramientas necesarias para que el control público sea eficaz. La hipótesis de trabajo sostiene que la única manera de garantizar que sean cumplidas las normas, que preservan la integridad, transparencia y equidad electoral, es a través de la aplicación de los mecanismos de control

\section{Acerca del autor}

Abogado por la Universidad de Buenos Aires. Magister en Dirección y Gestión Pública Local por la Universidad Carlos III y magister en Auditoría Gubernamental por la Universidad de San Martín. Director de Proyecto - Auditoría General de la Ciudad de Buenos Aires. Es el autor de: Mecanismos de fiscalización del financiamiento electoral, 2015; y Los procedimientos de control del financiamiento de las campañas electorales a cargo de las entidades fiscalizadoras superiores. El caso de la AGCBA, 2014. Dirección: Primera Junta 975. Haedo, Pcia. de Bs As - Argentina (cp 1706). Correo electrónico: richardgondorf@hotmail.com 
descriptos y complementariamente la viabilización de un sistema de penalidades equilibrado y efectivo.

Palabras clave: partido político; sistema de partidos; campañas electorales; financiamiento electoral; control del financiamiento de campaña.

\begin{abstract}
This article conceptualizes the essential meaning and functions of political parties and dive the reasons for its financing, centrally the election campaign. It develops existing objectives and constituent elements (express or implied) in any system of campaign financing, its skyline to preserve the integrity, transparency and electoral fairness. Different motives underlying both the public and private financing, highlighting the risks of the take over of the institutional representation by private and illegal purposes of such transfer of funds. On the second part, it describes the characteristics of the mechanisms of transparency, accountability and oversight, deepening the analysis necessary for effective public control tools. The working hypothesis argues that the only way to ensure that the actors be complied with the rules that preserve the integrity, transparency and electoral equity, is through the application of control mechanisms, in addition the viability of a balanced and effective system of penalties.
\end{abstract}

Keywords: political party; party system; election campaigns; campaign finance; control of campaign financing.

Artigo recebido em 30 de dezembro de 20I4; aceito para publicação em 17 de março de 2015.

\title{
Partidos políticos y representación
}

"El pueblo no delibera ni gobierna sino por medio de sus representantes y autoridades creadas por esta Constitución”, dice la Carta Magna argentina en su artículo $22^{\circ}$, sintetizando cabalmente la opción fundacional por un sistema de gobierno democrático indirecto. El representante institucional deberá ser entonces, por definición conceptual, el mediador entre el pueblo y la acción gubernativa.

Hay que admitir que esta característica asumida de "representación” fue modificándose a través del tiempo, al punto tal que, en la actualidad, tanto en Argentina como en la mayoría de los países de Occidente, sus sociedades cuestionan que esa "representación" haya dejado de ser un mecanismo de expresión o de defensa de distintos sectores de la sociedad, para convertirse en una "casta" o "clase" con intereses propios, que busca la legitimidad coyuntural en pos del 
poder. Y este proceso de recelo generalizado tiene como destinatario a la política en general y al partido político en particular, que es el vector central de la representación en las democracias modernas.

Aunque se da la paradoja que, si bien existan serios cuestionamientos sobre la eficacia del sistema democrático representativo en el logro del desarrollo integral de los pueblos, simultáneamente, se ha consolidado una cultura política que acepta los principios básicos sobre los que se asienta este tipo de sistema, de manera tal que el régimen político representativo partidocrático sea reconocido como "the only game in town".

Al respecto la Secretaría General de la Organización de los Estados Americanos (OEA) reconoce que nunca tantos países de la región vivieron, a la misma vez, tanto tiempo sin interrupciones autoritarias (OEA, 2013, 30). Sin embargo, ese organismo advierte que vigencia no es necesariamente sinónimo de fortaleza, por lo cual, la legitimidad de la democracia debe ser una construcción permanente a proteger. Nada lastima más a esa legitimidad que la percepción de las sociedades de la cantidad de deudas incumplidas por el mismo sistema en materia de desarrollo humano y el alto grado de inequidad social y económica dentro del continente. Este estado de situación incuba la apatía y anomia social; impulsa un peligroso descreimiento hacia los pilares del sistema representativo democrático, $\mathrm{y}$, entre ellos, especialmente hacia los partidos políticos.

No se pretende aquí hacer ni una apología ni una defenestración a los partidos políticos, sino subrayar su importancia como único vehículo institucional de la sociedad para acceder al poder. Destacando estos dos aspectos (relevancia y deslegitimidad) es que se entiende relevante poner la lupa en un aspecto fundamental de este vehículo: su financiamiento.

Atendiendo estos aspectos Prats I Catalá (2005) planteó que el camino a transitar en pos de superar este estado de situación crítico no debería sustituirse a los partidos, sino determinar las estrategias adecuadas para que ellos desempeñen lo que él llamó de buena política. En este sentido, enuncia diversas cualidades que debe tener el sistema partidario de un país a fin de producir ese tipo de buena política, capaz de fortalecer la unidad en la diversidad y de producir desarrollo humano. En el presente artículo, se pretende puntualizar sólo una de esas cualidades enunciadas para llegar a una buena 
política, a saber: el principio de financiación transparente, limitada $y$ con rendición de cuentas.

Se suele decir recurrentemente que, aunque la democracia no tenga precio, su funcionamiento sí tiene mucho costo económico. En ese marco, el proceso de acceso a la representación institucional y el desenvolvimiento posterior en esas funciones accedidas a través del apoyo ciudadano, merece situar al financiamiento de la actividad política como un eje del debate académico, político y público en general.

Es conveniente, entonces, precisar conceptualmente la idea de $f$ nanciamiento de la política ya que se puede definir en sentido amplio y en sentido restringido, pero para la incumbencia de este artículo se utilizará la definición restringida, por lo cual, al hablar de financiamiento político se estará haciendo referencia a los recursos -fundamentalmente de traducción económica-invertidos en el desarrollo de las campañas electorales de los partidos políticos. Recurrir a fuentes monetarias es de naturaleza normal en competencia democrática y también, tal como lo expresan Casas y Zovatto (2010), aunque de por sí no se trata de una patología, es innegable que el dinero puede introducir distorsiones importantes en el proceso democrático. Estos dos reconocidos autores usan una metáfora sumamente descriptiva al ubicarlo conceptualmente "entre la leche materna y el veneno".

Rápidamente, se pueden enunciar algunas de las muchas razones que explican contextualmente ese carácter dual de elemento indispensable y, simultáneamente, de potencial peligro letal, que tiene el financiamiento político:

a) La extensión geográfica y perdurabilidad de las instituciones y prácticas democráticas;

b) La relevancia del financiamiento privado, que es capaz de suplementar la participación y promover la competencia. Ante la verificación generalizada que el número de militancia activa disminuye cada vez más, el apoyo político individual y "ser parte de" pueden manifestarse alternativamente desde el aporte económico. Inclusive apoyos puntuales pueden facilitar la entrada en el juego competitivo a nuevas candidaturas. En Estados Unidos, en el año 2012 para la campaña de Barack Obama, las contribuciones de los pequeños donantes representaron el $28 \%$ de los aportes individuales totales, sumando 218 millones de dólares (Issacharoff, 2014); 
c) A medida que las elecciones se desarrollan paulatinamente, cada vez de manera más inclusivas, competitivas y limpias, se debe invertir mayor cantidad de recursos a fin de garantizar estándares adecuados de administración electoral realmente democrática, garantizando así sistemas competitivos y multipartidistas;

d) La polución de consultoras y el uso intensivo de herramientas publicitarias multimediáticas como epicentro de las estrategias electorales demandan muchísimos insumos económicos;

e) Todas las situaciones anteriores generan la necesidad de recaudar progresivamente más fondos, motivando instancias de encuentro entre quienes compulsan electoralmente y los posibles financistas. Instancias que, según sean los entornos de cultura política y de las corporaciones económicas, abren un posible abanico de riesgos de vulnerar los principios democráticos, de equidad y competitividad, como:

- quienes requieren fondos necesarios para lograr visibilidad y posicionamiento masivo (cual producto de consumo general) fundamentalmente a través de una fuerte presencia mediática;

- Incluso, también reiteradamente, suceden oportunidades en las que existen actividades extorsivas (promoviendo o no acciones administrativas o leyes) desde una posición de poder hacia quienes se niegan a aportar;

- quienes buscan, a través de sus aportes, tener una posterior posibilidad de promover sus intereses particulares en la agenda de gobierno, de modo tal que se intercambien fondos por cargos relevantes, favores especiales, influencias, compromisos, relaciones fluidas a los espacios de determinación política. Esta situación reviste una importancia crítica para la democracia, ya que el poder político va abandonando su función de estructurar a la sociedad alternativamente al poder económico para reducirse a reproducirlo;

f) En la historia de varios países, ha tomado estado público que, de esta manera, se conformaron caminos para que importantes recursos, producto de negocios del crimen organizado (tóxicos, armas, juego, prostitución etc.), se "blanquearan" como fondos de campaña a cambio de protección directa o indirecta;

g) La llamada "captura del Estado" significa no sólo lograr beneficios o privilegios puntuales, sino incidir en la orientación general de reglas para la comunidad. El financiamiento espurio 
de la política puede dar lugar a ello. El problema, además, es que así se profundiza la percepción social del quiebre del sentido de representación entre mandatario político y comunidad mandante, a favor de intereses de poder. Esta situación contradice los pilares ontológicos de la democracia y colabora con el creciente escepticismo por la política y descreimiento en los asuntos de interés público, incluyendo las propias elecciones;

h) La captura del Estado puede acarrear también prácticas de conservación del status quo, reproduciendo el sistema socio- político en sí mismo, haciendo abuso de recursos del Estado con fines políticos particulares o de sector, e incluyendo el uso y direccionamiento clientelar del tiempo y de los recursos de bienes y servicios públicos. Teniendo en cuenta que América es el continente con mayor desigualdad social y económica, existe una tendencia a la utilización de dinero con fines prohibidos, tales como clientelismo político que se manifiesta, por ejemplo, en la "compra de votos";

i) Con respecto a la posibilidad o no de competir, la posesión o no de cuantiosos recursos económicos puede significar, para ciertos grupos, barreras de entrada al proceso electoral. En ese sentido, una distribución de recursos groseramente inequitativa puede dejar afuera importantes sectores y afectar la legitimidad de los comicios.

Ya sea por los montos y/o por sus fuentes implicadas, lo enunciado deja a las claras la relevancia de los insumos económicos de las campañas políticas, y como se dijo en párrafos anteriores, está consagrado legalmente que sólo a través de los partidos políticos se accede al poder público durante el proceso electoral.

Es lógico, entonces, que se deba regular en el origen y destino de los fondos utilizados en dicho período. A dicha normatización, que regla las fuentes de dinero, los gastos posibles, la transparencia y la rendición de cuentas, se le llama Sistema de Financiamiento Político (SFP).

\section{El Sistema de Financiamiento Político (SFP)}

Sánchez Muñoz $(2014,4)$ propone extender el alcance del concepto de libertad del sufragio más allá de la órbita subjetiva del 
elector (libre de coacciones o presiones), para alcanzar al concepto de libertad objetiva de la elección, es decir, los ciudadanos pueden elegir entre auténticas alternativas, en el marco de un proceso previo verdaderamente informativo, libre de vicios por el abuso de influencia ejercido por parte de algunos de los contendientes; a decir de este autor español "libertad en sentido objetivo viene a equivaler así a la maximización de la competitividad del proceso electoral”.

Y precisamente un SFP se considera que es equitativo cuando regula los recursos de las campañas a fin de garantizar la igualdad de condiciones para elegir y ser elegido. Dicha regulación implica la restricción de aquellos recursos que perjudican o pueden perjudicar la igualdad de condiciones, así como la estimulación de los recursos que las favorecen.

Legislaciones de diversos países han previsto diversos mecanismos a fin de evitar o reducir influencias abusivas de algunos de los contendientes (por uso excesivo de dinero y publicidad, por uso de recursos ilegales o uso indebido de bienes públicos), a tal fin es que se han establecido distintos tipos de límites: a los ingresos de los partidos, a los tiempos de campaña, a los gastos electorales (topes máximos de gastos, límites a determinados tipos de gastos). Esos abusos que en definitiva distorsionan el derecho para que los electores puedan escoger en libertad entre diversas opciones políticas son considerados factores inválidos. Entonces un Sistema de Financiamiento, previendo ventajas eventuales que pueden llegar a tener ciertos candidatos, debe discriminar cuáles impactan de manera legítima en la competición y cuáles han de ser consideradas como abusivas. Por lo cual, los factores inválidos deberán ser minimizados, a través de normas limitativas o prohibitivas, son los casos de restricción del financiamiento privado y prohibición del desvío electoral de recursos públicos.

Paralelamente, en muchos países, a través de diversas estrategias de financiamiento público, se pretenden maximizar lo que entienden como factores válidos, en pos de favorecer la multiplicidad de ofertas electorales y su correspondiente actividad proselitista.

Tomando en cuenta esta suerte de tarea de articulación balanceada de factores válidos e inválidos que nos plantea Sánchez Muñoz (2010), se podría conceptualizar que el Sistema de Financiamiento Político se estructura alrededor de la defensa de los principios de equidad en la competencia y de transparencia e integridad electoral. 
Para lo cual pretende regular el flujo de fondos a fin de que se minimice la influencia de los factores inválidos y se maximice la de los válidos.

El modo de verificar que efectivamente existe en una jurisdicción esa voluntad concreta de proteger y estimular la equidad, transparencia e integridad en la competencia electoral es observando la normativa y efectiva estructuración institucional existente en lo referente a la rendición de cuentas de los sujetos políticos y cómo se ejerce el control gubernamental por parte de las instituciones estatales. Normativa que debe incluir un régimen sancionatorio para quienes infringen o incumplen ese marco jurídico específico del financiamiento.

Existe una idea pacífica sobre cuáles son los componentes alrededor que se instituye implícita o expresamente un SFP y cuáles son las subcategorías que lo componen (Navarro y Casas, 2005), a saber:

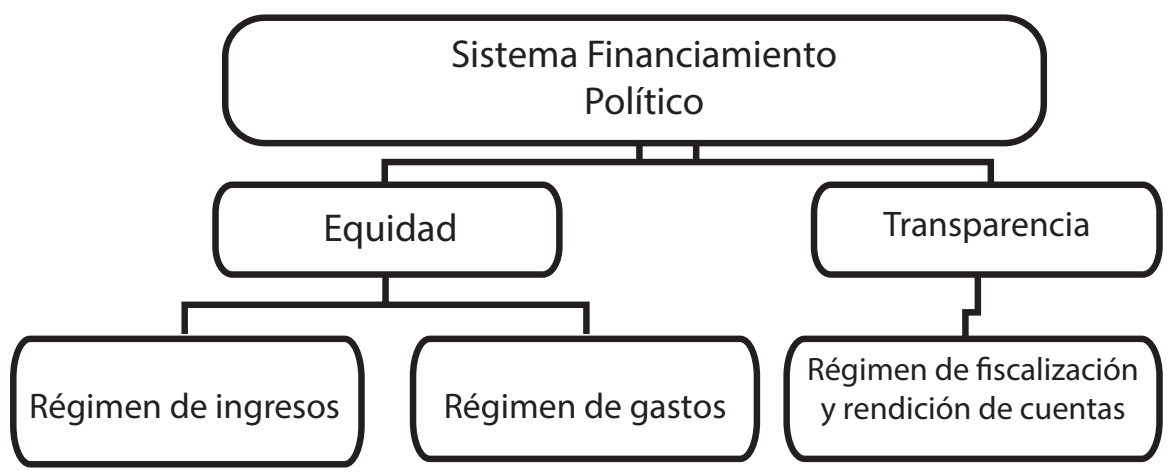

Se advierte de la lectura de titulares de periódicos que en muchos de los países de América se ha considerado el alto nivel de riesgo para la democracia que produce la inexistencia de regulación adecuada de estas categorías, por lo cual se ha pretendido avanzar en la cuestión normativa, aunque pareciera que sus resultados no han sido enteramente fructíferos aún. Habrá que tener presente que, como puntualizan certeramente los expertos en la materia, "todo esfuerzo regulatorio tiende a incrementar las expectativas de que las nuevas normas sean capaces al menos de moderar los peores abusos en esta materia. Las reformas fracasadas dejan un sedimento de desilusión y cinismo que se convierte en una barrera a nuevos 
intentos de regulación” (Casas y Zovatto, 2010). Por lo cual el diseño de esa normativización del financiamiento político debe atender las posibilidades concretas de acción y brindar un marco eficiente y actualizado; caso contrario, una regulación ineficiente puede ser tan negativa como su ausencia completa.

\section{Preservando la equidad. Regulando el financiamiento público de la política}

Ha dicho Navarro Fierro (2005) que, probablemente, sea la República Oriental del Uruguay quien comenzó a otorgar financiamiento público directo a través de una legislación de 1925, subvencionando estatalmente a los partidos para sufragar gastos de impresión de las papeletas electorales.

Este mismo autor califica al régimen de financiamiento político con fondos públicos como regulación con carácter positivo, en la pretensión de propender a través de esta modalidad una influencia favorable para la competitividad y transparencia del sistema político electoral y señala que "a Puerto Rico le corresponde el mérito de haber sido el primer país en adoptar, en 1957, un sistema de financiamiento público directo para los partidos que pronto tendría eco en el universo de las democracias desarrolladas, pero que se extendería de manera muy gradual en el resto de América Latina" (Navarro Fierro, 2005, 15).

En la actualidad, 16 de los 18 países latinoamericanos consagran normativamente regulaciones que establecen distintos mecanismos de entrega de recursos del Estado para el financiamiento de campañas electorales (a excepción de Venezuela y Bolivia ${ }^{1}$ ). Esta enorme mayoría explica que los recursos públicos sean considerados en tanto realización del interés público y apartándose de los intereses privados, con pretensión de imparcialidad, y explica también los variados mecanismos de transferencia de recursos estatales para financiamiento de campañas políticas.

Se suele polemizar a favor y en contra de esta modalidad de financiamiento de la actividad política (Gruenberg, 2007), como sucede con toda cuestión relacionada con las finanzas públicas donde

1. Aunque en el caso de Bolivia sí tiene financiamiento público indirecto. 
existen mecanismos cuyo norte es la equidad en las condiciones de competencia, corrigiendo las distorsiones originadas en el financiamiento privado.

Los argumentos de sus detractores aseguran que el Financiamiento Público:

a) no redujo sino que incrementó los montos económicos totales usados en las contiendas electorales;

b) no sustituyó el financiamiento privado en términos absolutos ni redujo considerablemente la dependencia a grandes donantes;

c) sin dejar de depender de los grandes donantes, ahora se agrega la dependencia del Estado;

d) relaja y debilita la relación de los partidos con sus miembros;

e) en vista que es diseñado y aplicado por quienes detentan posiciones de poder institucional, ese sistema no suele ser verdaderamente equitativo, creando barreras de entrada a nuevas candidaturas o expresiones;

f) fomenta el "aventurerismo" político.

Por el contrario, los argumentos de los defensores de este sistema aseguran que el Financiamiento Público:

a) permite a las candidaturas tener un mínimo de seguridad y previsibilidad de recursos que permiten planificar una estrategia y actividades de campaña adecuadas;

b) libera y protege a las candidaturas de la posible incidencia de grandes donantes o donantes de fondos ilegales;

c) evita que quienes tienen enormes recursos económicos dominen desproporcionadamente la competencia electoral, en detrimento de otras postulaciones que no cuentan ni de cerca con recursos para hacerse conocer;

d) adecuadamente implementado, resguarda la equidad en la visibilización política y la comunicación proselitista.

Lo cierto es que el Financiamiento Político Público es el mecanismo regulatorio "positivo" más diseminado y antiguo, verificándose su aplicación centralmente de dos maneras: el Financiamiento Público Directo y el Financiamiento Público Indirecto. En el primer caso, la 
instancia estatal correspondiente hace entrega de dinero a fin de que los partidos políticos puedan cubrir determinados gastos electorales. Dichas entregas pueden tener un cargo específico a invertir (como el caso de cubrir los gastos de impresión de boletas electorales), o pueden sufragar cualquier actividad electoral. En el segundo caso, el financiamiento público indirecto es otorgado en especie; tal como apoyo para la difusión (correo), beneficios tributarios, subvenciones a grupos parlamentarios (se usa en Europa), uso gratuito de inmuebles e infraestructura pública (carteleras), y lo que es más oneroso: tiempo y espacio gratuitos en los medios de comunicación.

Ahora, al momento de evaluar las categorías de cada Financiamiento Público Político y sus características hay determinadas variables que deberían ser consideradas, ya que condicionan el cumplimento real de los objetivos de equidad, en ambas modalidades de financiamiento público:

a) El mecanismo a través del cual se determina el monto a recibir por cada fuerza política, que debe ser objetivo, no discrecional y de suficiencia económica;

b) Criterio de distribución de los fondos entre los contendientes, es decir, si tendrá en cuenta la sola aptitud legal para entrar en la contienda (igualdad absoluta) y/o la cantidad de votos o escaños obtenidos por cada fuerza política en una elección anterior (igualdad proporcional). Si se usa sólo el primer criterio, se estimulará a la atomización de contendientes, y si se opta por utilizar sólo el segundo, se estimula la permanencia en el tiempo de una situación política quizás coyuntural, restando posibilidad de nuevos escenarios, por lo cual, se recomienda utilizar una combinación de ambos criterios;

c) Oportunidad en que se hace entrega del financiamiento, ya que los montos pueden entregarse durante la campaña o $a$ posteriori, como reembolso de lo gastado. La modalidad influye en la equidad en la competencia, ya que contar o no con los medios económicos suficientes al comienzo de la campaña determinará si se podrá o no contratar los diversos servicios de propaganda y publicidad electoral;

d) Orientación del destino de los recursos públicos, de tal manera que se pueda favorecer la equidad de determinados grupos o sectores considerados cultural, social o económicamente más 
desfavorecidos, hacia adentro de cada agrupamiento político (como dar un \% adicional de fondos públicos al partido cuanto más mujeres candidateen);

e) Un aspecto muy relevante a tener en cuenta es el nivel de eficacia de las instancias de gestión pública para cumplir que las fuerzas políticas accedan en tiempo y forma al financiamiento público, en cualquiera de sus formas.

Los recursos estatales están vinculados al interés público y no a los intereses privados, por lo que en principio serían imparciales. Y esto es así porque cuando se cumplen cabalmente reglas de juego claras y objetivas en la entrega de tales recursos, éstos tienen una fuerte posibilidad niveladora de las condiciones de la competencia política. Si se complementan con restricciones adecuadas al financiamiento privado y se cumplen los límites a los gastos de campaña, el SFP generaría las condiciones necesarias para reducir las asimetrías en la pugna del acceso al poder.

El problema usual es cuando se verifica que los recursos del Estado son utilizados con fines político-electorales particulares, desequilibrando así el sistema de financiamiento, debido a que los recursos públicos pierden así imparcialidad y acentúan la inequidad en la competencia. Cuando quienes detentan el poder hacen uso de su posición privilegiada y logran una ventaja determinante, se destiñen los objetivos y el marco regulador mismo de financiamiento político. Ante estos riesgos, algunas legislaciones de la región ya contemplan prohibiciones expresas que limitan el uso de recursos del Estado y la participación de funcionarios en campaña electoral, aunque "la delgada línea que divide los actos de campaña de las actividades propias de la gestión de los funcionarios del Estado hace muy compleja su regulación en la práctica. Uno de los ejemplos más claros de esta situación es el uso de programas sociales y subsidios en época electoral" (OEA; IDEA e IFE, 2013).

Es en idéntico sentido que, en tiempos cercanos a la elección, la publicidad de la inauguración de obras o lanzamiento de programas se convierte de hecho en una especie particular de ventaja indebida de unos competidores sobre otros. Por ello aunque se exprese que el objetivo de esos eventos no es proselitista, la prohibición de publicidad sobre ese tipo de asunto estatal durante la campaña 
electoral puede ser una traba al aprovechamiento propagandístico de "logros" oficiales.

Por ello a simple modo enunciativo, se podría nombrar como modalidades comunes de uso arbitrario de los recursos públicos: a) el uso de programas sociales con fines electorales; $b$ ) las donaciones ilegales a partidos por parte de órganos oficiales; c) la utilización de recursos humanos e infraestructura pública en las campañas de los candidatos oficialistas; d) el ejercicio abusivo del poder de contratar servicios de empresas; e) los gastos en transporte, materiales propagandísticos y medios de comunicación estatales; y f) la compra de votos y el clientelismo político.

Casi en momentos de terminar la confección de este artículo, el Gobierno federal mexicano y el Órgano Nacional Electoral (INE) celebraron un acuerdo a fin de "proteger los recursos públicos de los programas sociales del Gobierno de la República y evitar que sean utilizados con fines políticos o electorales". Es interesante un análisis de esta iniciativa que menciona una consulta a un grupo de expertos locales de cada estado, quienes evaluaron como la más extendida práctica de defraudación electoral en las elecciones de gobernador en ese país (periodo 2001-2012). Una de las menciones mayores fue el uso de recursos públicos en beneficio del candidato oficial (Nicolás Loza, 2015).

\section{Acerca del financiamiento privado}

Desde los lejanos tiempos en que el sistema democrático representativo consagró a los partidos políticos, el tema de su sostenimiento y del financiamiento de las campañas electorales tuvo eje en los aportes de los sectores privados; sean éstos afiliados o simpatizantes, sectores pudientes, empresarios, obreros, movimientos sindicales y/o políticos locales o inclusive internacionales. De este modo las campañas electorales suelen contar con la contribución de personas naturales y jurídicas, a fin de apoyar a la opción política de su preferencia. Ante la retracción de la militancia activa, la fórmula "muchos aportantes de poco dinero" de algún modo revincula a las agrupaciones políticas con los ciudadanos.

El problema es que, generalmente, no ocurre así, y en sociedades desiguales estos aportes son efectuados por pocas personas y grandes montos, trasladándose así las asimetrías estructurales a la 
competencia electoral. Esta situación agravada a veces por el origen de estos aportes conspira, de hecho, contra la máxima de "una persona, un voto", por lo se hace necesario restringir los tipos de usos, fuentes y montos de las contribuciones a fin de preservar básicas condiciones de competencia equitativa.

España muestra un ejemplo claro de las desastrosas consecuencias por no limitar determinadas formas de financiamiento privado. El Grupo de Estados contra la Corrupción del Consejo de Europa (GRECO), en su informe de lucha contra la corrupción de febrero de 2014 expresa que en aquel país europeo "durante los años de prosperidad económica, los partidos políticos recurrieron ampliamente a préstamos bancarios para sufragar sus gastos. El Tribunal de Cuentas señalaba en 2012 que la deuda total de los partidos políticos (de ámbito nacional y autonómico) con entidades financieras ascendía a 227 millones de euros en 2007”. Es más, en sus informes de 2011 y 2013 el GRECO también manifestó la necesidad que se garantice que las fundaciones y asociaciones vinculadas a los partidos políticos (que no están obligadas a informar sobre sus gastos) no se utilicen como vía paralela para financiar actividades corrientes y de campaña electoral.

Otro ejemplo observable es el caso estadounidense. En su informe Política, dinero y poder: una dilema para las democracias, la OEA (2011) anuncia que la dinámica del financiamiento de campañas presidenciales en Estados Unidos experimentará cambios considerables hacia dos direcciones contrapuestas: una democrática y otra plutocrática.

Por un lado, la experiencia de las dos campañas presidenciales de Obama ha mostrado el enorme potencial de internet para democratizar el financiamiento político mediante la contribución de millones de pequeños aportantes. En la campaña de 2008 tres millones de individuos aportaron 6,5 millones de dólares, de los cuales 6 millones fueron aportados por contribuciones de menos de 100 dólares.

Pero en un sentido diametralmente opuesto, el fallo del año 2010 de la Corte Suprema de Justicia de los Estados Unidos en el caso Citizen United $v s$. Federal Election Commision ha dado por tierra una tradición observada en ese país desde los años 70, haciendo desaparecer, así, las limitaciones de financiamiento en los montos y en la participación de las empresas en favor o en contra de candidatos y partidos contendientes bajo pretexto de proteger "la libertad 
de expresión”. Por ello, expertos internacionales de esta temática alertan sobre el ejemplo pernicioso que esta resolución pueda tener para los países de la región.

Por el contrario, para la orientación que aquí se sostiene, un Sistema Electoral debe tender siempre como principio la equidad, integridad y transparencia en la competencia. Por lo cual, todo Sistema de Financiamiento Político debe comprender un régimen de ingresos cuyo indicador sea la restricción del financiamiento privado para minimizar a tal fin la influencia de los factores inválidos capaces de distorsionar el atributo equitativo del proceso electoral. Aclarándose que los factores distorsivos son recursos que pueden vulnerar los principios democráticos elementales, en tanto causan riesgos de interferencias externas o de injerencia indebida a autoridades públicas, de corruptelas o tráfico de influencias, de defensa de intereses de grupo. Y si la utilización de los recursos económicos con origen lícito en las campañas ya es un problema para las democracias de masas, el empleo de los que tienen origen ilícito afecta al conjunto de los principios democráticos que deben ordenar los procesos electorales. Su principal instrumento es la compra de votos, que afrenta la libertad de voto, la autenticidad electoral y el principio de la igualdad de oportunidades (Salgado, 2012). En este sentido, más razones existen para formular un diseño que impida totalmente el ingreso de fuentes ilícitas como las procedentes del crimen organizado.

Es en este último tema que la clase política de los países de la región parecieran no advertir el peligro no ya latente sino efectivo de como, por ejemplo, el dinero del narcotráfico ha filtrado en las campañas electorales, como la tímida intención de diputados paraguayos para evitar que el dinero del crimen organizado sea utilizado en las campañas políticas ha sido recientemente "encajonada" por el senado de aquel país, con la anuencia del Tribunal Superior de Justicia Electoral (TSJE). El proyecto de ley pretende prohibir que personas acusadas o condenadas por delitos de narcotráfico, lavado de dinero o evasión de divisas puedan contribuir para las campañas electorales de los partidos y candidatos. Las sanciones previstas incluyen la reducción del aporte público electoral ${ }^{2}$.

2. Ver diario $A B C$. Disponible en: http://www.abc.com.py/edicion-impresa/politica/ anr-y-plra-frenan-control-de-dinero-narco-en-comicios-1343279.html 
En las últimas elecciones de Perú del año 2014, la oficina de la procuradora antidroga de ese país, Sonia Medina, detectó a 700 postulantes investigados, enjuiciados o condenados por delitos vinculados con el narcotráfico. "Creo que los organismos competentes deben adoptar acciones urgentes frente a ese tipo de casos. Me refiero a los organismos electorales, pero también a los partidos que tienen una responsabilidad, no se trata solo de recibir cupos económicos, sin importar su procedencia, sino que en su grupo haya gente de valía”, dijo Medina a la agencia Andina. Según la procuradora no alcanza con separar a un candidato del partido, sino que debe producirse nueva legislación que prescriba sanciones económicas y políticas a las agrupaciones que tengan en sus filas a personas relacionadas con el narcotráfico y el crimen organizado.

Estos son sólo ejemplos de dos países, pero de relevarse todos los de la región veremos en cada uno, en más o en menos, repetida esta gravísima problemática. Ya viene siendo tiempo que desde los distintos órganos públicos (fuera y pertenecientes a la cuestión electoral) se tome debida nota y se tracen estrategias que obturen esta posibilidad de filtración del sistema político.

Por lo pronto deberían cumplirse cabalmente los límites o restricciones ya existentes a los aportes o donaciones privados. En esta dirección se pueden encontrar restricciones a las donaciones o aportes privados por origen o por monto. Entre los llamados límites por origen se pueden encontrar: a) prohibiciones sobre donaciones del extranjero; b) prohibiciones sobre donaciones anónimas; c) prohibiciones sobre donaciones de empresas (o personas jurídicas) $\mathrm{y}$, dentro de estas: $\mathrm{c}_{1}$ ) aquellas con vínculo contractual con el Estado (proveedores, concesionarios); $\mathrm{c}_{2}$ ) prohibiciones de personas colectivas, políticas o sociales; y $\mathrm{c}_{3}$ ) prohibición de donaciones de los medios de comunicación.

En cuanto a las restricciones de aportes privados por monto, existen límites en la cantidad de donación por persona y límites del total a recibir por candidato, categoría o partido. El objetivo de esta limitación es claro, pues se busca evitar una concentración y su consecuente dependencia del financiamiento electoral en unas pocas manos - corporaciones, grupos o individuos de poder económico. En segundo lugar se pretende diversificar las fuentes de financiamiento privado, de modo tal que los partidos se esfuercen en conectar con la sociedad y procuren convertir la adhesión o simpatía política en 
contribución monetaria. Y el tercer objetivo de esta restricción -no menos relevante- es también reducir los costos de campañas.

Como ya se ha expresado en otra oportunidad (Gonzalez Dorfman, 2014), a la luz del análisis comparado el consenso más generalizado es que para que un sistema sea equitativo deberá ser mixto, de modo tal que, en virtud de suficientes recursos públicos se garanticen condiciones básicas de equidad en la competencia electoral, y deberá posibilitar también el financiamiento privado, de manera tal que - en su medida correcta - se pueda preservar la extensión del derecho a expresarse, a elegir y a fortalecer la representatividad. Este sistema mixto será equitativo de articularse con claros límites a los gastos de las campañas. La adecuada restricción de los gastos electorales opera a partir de la dilatada experiencia del riesgo de desmedidos aumentos de los costos totales de la campaña; ya sea por el financiamiento público, por el privado, o por el efecto aditivo.

Los límites de gastos operan como un nivelador de las condiciones de la competencia, pues contribuyen a la equidad de oportunidades entre los que cuentan con las herramientas para recaudar fondos con los que no. Y procuran minimizar los factores inválidos en la compulsa, como ser una ventaja considerable, producto de una fuerte disparidad en la disponibilidad de recursos financieros.

En sintonía con el "laissez faire" norteamericano para los ingresos de campaña, su jurisprudencia es favorable al no límite de las erogaciones electorales. Desde el fallo Buckley vs Valeo (1976) el máximo tribunal de aquel país entendió que los gastos de campaña son para comunicar y expresar las ideas de los candidatos, por lo cual toda financiación a la libre expresión no se debe restringir, sino que se debe preservarse.

Con respecto a la articulación de las restricciones de ingresos con las de gastos, hay una "curiosidad" en las regulaciones de nuestra región ya que si bien existen una numerosa variedad de restricciones al financiamiento privado, en la mayoría de los países no hay una concordancia con límites a los gastos de campaña. Es que, para hacer efectivas la fijación de barreras a los gastos y éstas no se conviertan en incentivos para hacer fraudes registrales y canalizar fondos extra por vías paralelas, se debe contar con una decisión político-institucional que establezca un muy eficiente y robusto sistema de control (Ferreira Rubio, 2012). 
Por ello, afortunada (expresado desde una mirada más igualitaria) y paulatinamente hay países y jurisdicciones subnacionales que van optando por dotar de mecanismos de control a sus sistemas de financiamiento político y van estableciendo límites de los costos totales de las campañas, ya sea a través de estrategias de restricción directa como indirecta:

- Las formas directas son las que establecen topes de gastos por formaciones políticas o candidatos. Para que sean efectivos se debe evitar cualquier grado de discrecionalidad en su estipulación, por lo cual se requieren que estos límites tengan como características ser explícitos, objetivos y medibles;

- Las formas indirectas son estrategias que procuran reducir gastos a través de impedimentos de tiempo o de especie, siendo los límites de duración de la campaña y la restricción parcial o totalmente de la contratación de los llamados "disparadores del gasto" (rubros que aumentan exponencialmente los gastos de la campaña electoral, tales como publicidad en medios de comunicación).

a) Los límites de duración de la campaña consisten en establecer el lapso en el que se permite el proselitismo electoral, con el objetivo de que los costos se reduzcan, al reducir el período en el cual cada fuerza política produzca sus gastos. Esta estrategia es válida, aunque presenta dos inconvenientes: el primer riesgo es que puede estimular la concentración de los gastos en los períodos legalmente permitidos; el segundo es que los candidatos lleven adelante tareas de visibilidad o instalación de imagen con una "campaña encubierta", por ejemplo, utilizar carteleras o aparecer en medios audiovisuales, sin consignar candidatura. Es imprescindible entonces, implementar estos tipos de límites complementando con otros mecanismos que tengan la misma orientación.

b) Hay muchas experiencias de países que han legislado limitaciones a los "disparadores del gasto". La norma electoral federal argentina, por ejemplo, engloba y enuncia esos mecanismos: los medios masivos de comunicación (televisión, radio e Internet), vía pública, medios gráficos, telefonía móvil y fija, publicidad estática en espectáculos deportivos o de cualquier 
naturaleza, así como también la publicidad alusiva a los partidos políticos y a sus acciones.

Es interesante cómo en el caso federal argentino está prohibida la contratación privada de propaganda proselitista entre cualquier contendiente y radio o televisión antes de los veinticinco días previos a la fecha fijada para el comicio (reducción de hecho de la duración de campaña); también durante el resto de los días hasta la elección está prohibida la contratación privada (limitaciones al disparadores del gasto), pero el Estado les otorga, durante ese lapso, espacios gratuitos que les permiten una importante presencia en esos medios (financiamiento público indirecto). Este ejemplo es una articulación de límites combinada con una compensación de financiamiento público indirecto. Si existiera una clara normativa y un férreo control antes del período determinado para campaña audiovisual electoral (25 días antes de la elección) los costos de gastos se reducirían drásticamente.

Para concluir este apartado habrá que tener en cuenta la enorme relevancia de la cuestión mediática y de las llamadas redes sociales. Más temprano que tarde, no podrá ser ajeno de la legislación ni de la atención de los organismos de control, el uso del Internet, de las redes sociales como espacios de discusión política y de propaganda electoral.

\section{Un régimen de transparencia, con rendición de cuentas y eficaz control público}

Cuando antes se determinaron los dos atributos centrales del SFP, se puntualizó en la Equidad y la Transparencia. Es harto evidente que se estaría hablando sólo de estos atributos como ideales abstractos de no complementar el mismo SFP con un debido ambiente de control, es decir, un régimen de rendición de cuentas y fiscalización a la altura de esta importante tarea. Sin dudas, el régimen que norme el financiamiento electoral debe regular también la puesta en disponibilidad de la información sobre el origen y destino de los recursos utilizados.

Ferreira Rubio (2012) puntualiza la importancia en el conocimiento y compromiso ciudadano a la hora de votar. El llamado "voto informado" presume que la ciudadanía debe conocer quién o qué intereses está detrás de cada candidato; quiénes o cómo financian 
su campaña. Teniendo, así, que el valor a tutelar es la transparencia como componente indispensable de la competencia electoral se incorpora un requisito más a los hasta aquí expresados. La doctrina internacional ya incorporó como condición el acceso público a la información, situación que también deberá ser contemplada normativamente en cada jurisdicción.

Cuando se habla de transparencia del sistema de financiamiento electoral se está refiriendo a las siguientes condiciones que necesariamente deberían estar específicamente normadas: rendición de cuentas; control oficial y acceso público a la información; régimen sancionatorio.

\section{a) Rendición de cuentas}

La rendición de cuentas es el procedimiento mediante el cual cada agrupación política o candidato pone a disposición de los organismos de control, y a la ciudadanía, la información sobre el flujo de recursos de sus campañas. Ese procedimiento, que puede implementarse mediante tracto sucesivo o de una sola vez, se consiste generalmente en la exposición de los de registros de los ingresos y egresos, de administración de los recursos, reportes financieros integrados y documentación (recibos, constancias, muestras, extractos bancarios etc.) de soporte de la información ofrecida.

\section{b) Control público}

El control público supone el desarrollo de medios institucionales necesarios, que puedan implementar cabalmente mecanismos de revisión, verificación y auditoría de los recursos. La normativa (constitucional o legislativa) de cada país define a quién o a quienes les corresponde efectuar estas tareas de control.

Este es una instancia crucial y de máxima significancia en el SFP. La eficacia de este control dependerá del bien jurídico que se pretenda expresamente tutelar, de la densidad normativa que oriente el funcionamiento y de los recursos (materiales, técnicos y humanos) del sistema. Esa conjunción determinará qué tipo de funciones, capacidad y competencia tendrá para 
poder fiscalizar el flujo real de recursos de las campañas de los partidos.

En un interesante aporte, hecho por Irazábal Alonso Lujambio (2007) sobre los mecanismos de control público de las finanzas políticas, se clasifican dos grandes tipos de instrumentos de control -directo e indirecto- con una "subespecie" que adquiere identidad propia por su complejidad, su relevancia y su casi inexistencia dentro de las legislaciones de los distintos países.

Cuadro I - Instrumentos de control del financiamiento político.

\begin{tabular}{|l|l|}
\hline $\begin{array}{l}\text { Instrumentos de } \\
\text { control directo }\end{array}$ & $\begin{array}{l}\text { Auditoría legal y contable sobre documentación pre- } \\
\text { sentada }\end{array}$ \\
\hline \multirow{2}{*}{$\begin{array}{l}\text { Instrumentos de } \\
\text { control indirecto }\end{array}$} & Monitoreo de gasto \\
\cline { 2 - 2 } & Publicidad de la información financiera \\
\cline { 2 - 2 } & Coadyuvancia de otras autoridades \\
\hline \multirow{4}{*}{$\begin{array}{l}\text { Instrumentos de } \\
\text { investigación }\end{array}$} & $\begin{array}{l}\text { Acceso a información restringida por secreto bancario } \\
\text { y financiero }\end{array}$ \\
\cline { 2 - 2 } & $\begin{array}{l}\text { Obligación de terceros informar de manera fehaciente } \\
\text { y veraz }\end{array}$ \\
\cline { 2 - 2 } & Solicitud de informe de autoridad fiscal / uif \\
\hline
\end{tabular}

Fuente: Elaboración propia en base a Alonso Lujambio, 2007.

El instrumento de control directo más utilizado es la auditoría de cumplimiento legal y financiero, y su ámbito de injerencia se circunscribe a los procedimientos de control formal de la documentación que cada fuerza política entrega. Evidentemente, con este tipo de auditoría a las finanzas formales es muy difícil detectar si el partido incumplió las normas y las esconde, falseando los registros contables.

A fin de procurar entonces una estrategia que permita detectar esas conductas ilegales, se implementan otros mecanismos, que son los llamados instrumentos indirectos de control. Entre los más relevantes encontramos:

- El monitoreo de gasto. Se trata del mecanismo que verifica externalizaciones de gastos no reportados (en número o en especie) por la agrupación política. De ellos se puede inferir ingresos no reportados. Este mecanismo tiene de hecho cierto límite porque detecta el gasto multimediático y en la vía pública, que es el que deja huella; 
- La publicidad de la información financiera de los partidos políticos. La "desclasificación" aún no ha tomado demasiada relevancia como instrumento indirecto, aunque tiene un potencial enorme. Por supuesto que generar tan cantidad de información trae el riesgo que no los puedan asimilar ni los órganos de control, ni los medios de comunicación, ni mucho menos los votantes (Zovatto, 2004). En realidad, la utilidad de esa información dependerá también del grado de conocimiento, como del nivel de conciencia social de las reglas de financiamiento, del nivel de claridad con que se elabora y transmite masivamente la información desclasificada, de la posibilidad de interacción que el ciudadano tenga con el órgano de control para sumar información a lo publicado y de la capacidad de la autoridad electoral para investigar la verdad;

- La articulación colaborativa con otras instituciones oficiales, que busca romper la generalizada cultura administrativa del "compartimento estanco", promoviendo la cooperación a partir del intercambio de datos propios de sus funciones; o también poder detectar un riesgo y hacérselo saber al organismo de control. Sin resignarse al uso de esta herramienta, no hay que caer en una mirada ingenua, y debe preverse el vínculo o interés personal o de sector con quienes se pretende articular, y el agrupamiento político que se pretende controlar.

Habrá que reconocer que, en esta época, de profesionalización de la política las irregularidades no suelen dejar huellas fácilmente visibles. Por ello, completando el círculo del control, es muy importante el uso de herramientas de investigación, entre las que distinguimos:

- La obligación de toda persona natural y/o ideal que fuera proveedora de bienes y servicios de responder los requerimientos de información que la autoridad de control le haya formulado en el ejercicio de su investigación sobre las prestaciones efectuadas a las agrupaciones auditadas;

- La inoponibilidad del resguardo informativo por los secretos bancario y fiscal;

- La articulación y solicitud a la instancia oficial pertinente, para que realice una investigación a determinada persona, a 
fin de obtener mayor cantidad de información para aclarar un hecho sospechoso.

- No se debería cerrar este apartado de herramientas de control sin considerar una herramienta no institucionalizada debidamente en la mayoría de los países, pero que, paulatinamente, viene desarrollándose en diversos países de la región, como es el accionar de lo que se suele llamar las organizaciones de la sociedad civil; aquellas que por conocimiento específico de sus integrantes fruto de la militancia de sus objetivos se han especializado en observar distintos aspectos de los procedimientos electorales. Es necesario que su actividad sea "puesta en valor" social, es decir, no sólo reconocida legalmente, sino que también preservada y estimulada. Al respecto Speck y Pfeiffer $(2007,34)$ enunciaron posibles modalidades de intervención de dichas organizaciones en materia de financiamiento de la política: divulgación de datos prestados voluntariamente; análisis y divulgación de datos oficiales; recolección de datos por medio de terceros; monitoreo de la publicidad en los medios; monitoreo de la actividad periodística; monitoreo de la publicidad externa.

Finalmente, en este artículo se parte de la premisa de que ninguna de estas herramientas, por sí solas, de manera individual, logrará controlar y detectar todas las acciones desviadas de la ley. Sin embargo, no caben dudas de que, al articular entre mecanismos directos e indirectos, con la posibilidad de complementar o profundizar el estudio a través de instrumentos investigativos, es posible establecer un ambiente de control adecuado del financiamiento del sistema político.

\section{c) El régimen punitivo y la existencia de sanciones}

El autor salvadoreño Félix Ulloa $(2004,112)$ asegura que la real vigencia de un régimen de financiamiento político requiere normas que fijen inequívocamente su objeto y alcance, el organismo de aplicación y fiscalización, los sujetos obligados, las sanciones o penalidades derivadas de su incumplimiento, y los procesos jurisdiccionales y administrativos necesarios para su aplicación y cumplimiento. Dicho autor, después de un estudio comparado sobre 
regímenes de sanciones en los sistemas de financiamiento político en Latinoamérica, advierte que, hasta que las naciones de la región lleguen al estado de real desarrollo del estado de derecho (sin prácticas evasoras y fraudulentas) se impone el establecimiento de un marco regulador suficientemente estricto como asegurar su cumplimiento.

No se desarrollará aquí mucho este tema, pero se resaltará que muy poco se logrará en persuadir a los contendientes políticos sobre el cumplimiento de las normas si en el mismo SFP no existe un preciso y adecuado régimen de sanciones, de manera tal que su operatividad eficaz promueva una cultura de rendición de cuentas y cumplimiento de las normas en general. Este régimen deberá lubricar tipos de castigo, mecanismos procesales y autoridad de aplicación.

Las distintas escalas de sanciones por aplicar ante eventuales actos irregulares o ilegales relacionados al SFP deben estar clara y debidamente expresadas (principios de legalidad y reserva de la ley). Los tipos penales pueden incluir sanciones de tipo administrativas, pecuniarias o penales, aplicadas a personas físicas determinadas (candidatos, autoridades partidarias) o a personas jurídicas (partidos o expresiones políticas diversas).

Por su parte, a través de los procedimientos o mecanismos procesales se aplican los castigos a quienes se les han imputado las trasgresiones tipificadas. Este tipo de reglas deben formularse para todos los casos de sanciones. Además de la aplicación de la sana crítica, los estándares adecuados para establecer las penalidades de quienes infringen las normas deben necesariamente contemplar el carácter sumario, la debida defensa y la oralidad en los procesos.

Finalmente, como en el caso del organismo de control, la autoridad de aplicación de las normas punitivas, sea de naturaleza judicial o administrativa, es la pieza angular para éxito de esta función. Esta instancia debe contar con suficiente independencia e imparcialidad política y financiera para desempeñar su función de un modo eficaz, lo que necesariamente significará -entre otras cosas- un número adecuado de recursos técnicos calificados.

\section{Conclusiones}

Es posible que los sistemas de financiamiento políticos funcionen de manera adecuada, eficiente en promover y preservar la equidad y 
transparencia electoral, que son los principios rectores que legitiman a las autoridades que acceden a sus funciones por el voto popular.

Para ello, es necesaria la existencia de una densidad normativa acorde a estos bienes sociales que contemple debidamente el financiamiento público electoral, que regule específica y arteramente el financiamiento privado y que limite adecuadamente los gastos. Sobre todo que se instituyan mecanismos y procedimientos de control muy robustos, que quienes los desarrollen cuenten con herramientas de control directo, indirecto y herramientas de investigación, dándose la oportunidad de interactuar también con la ciudadanía, y que se complemente con un plexo punitivo, serio y ejemplar acorde a la importancia del bien jurídico, social y democrático que se está pretendiendo tutelar.

Se trata de una política de Estado que requiere fuertes consensos, es decir, para "hacerlo carne" en cada sociedad es preciso debatirlo muy profusamente, para llegar a acuerdos de la clase política y de la comunidad toda poniendo en claro cuáles son esos bienes jurídicos que se quieren defender y asumiendo entre todos el esfuerzo institucional para lograrlo. De esta manera, será una pelea muy dura que afectará muchos y fuertes intereses, pero está en juego ni más ni menos que la legitimidad de la democracia.

\section{Referencias}

CASAS, K. (2005). Regulando el financiamiento de las campañas: mitos, límites y propuestas. Banco Mundial.

CASAS, K.; ZOVATTO, D. (2010). Para llegar a tiempo: apuntes sobre la regulación del financiamiento político en América Latina. Nueva Sociedad, n. 225, ene./feb. ISSN: 0251-35.

FIERRO, C. N. (2005). Regímenes de financiamiento y fiscalización y garantías de equidad en la contienda electoral estudio comparado de 19 países de América Latina. 1. ed. México: IFE- OEA. ISBN 970-695-122-9.

GRUENBERG, C. (2007). El costo de la democracia: poder económico y partidos políticos. Buenos Aires: Capital Intelectual.

GUTIÉRREZ, P.; ZOVATTO, D. (coord.) (2011). Financiamiento de los partidos políticos en América Latina. México: OEA-UNAM. ISBN 978-607-02-2355-6.

IRAZÁBAL, A. L. (2007). La fiscalización de los gastos de los partidos políticos. En: NOHLEN, D. et al. (comps.). Tratado de Derecho Electoral comparado de América Latina. 2 ed. México: Instituto Interamericano de Derechos Humanos. ISBN 978-968-16-8283-5. 
ISSACHAROFF, S. (2014). El rol de los pequeños donantes en las campañas políticas hoy. En: Seminario Internacional Estrategias de Recaudación de Fondos para las Campañas Electorales: Oportunidades y Limitaciones. Cippec-Rap-Poder Ciudadano.

LOZA, N. (2015). Blindaje e integridad electoral. Animal Político. Publicación digital mexicana. Disponible en: [http://www.animalpolitico.com/blogueros-blog-invitado/2015/03/12/blindaje-e-integridad-electoral/]. Visitado el: 29 de julio de 2015.

MUÑOZ, Ó. S. (2014). La igualdad de oportunidades en la competición electoral. En: V CONGRESO IBEROAMERICANO DE DERECHO ELECTORAL, 2014. Teresina: Instituto Iberoamericano de Derecho Electoral de la Universidad Federal de Piauí; la Ordem dos Advogados do Brasil.

PRATS I CATALÁ, J. (2005). Exposición central en panel de debate Desbloquear la Política. La Paz: Fundación Boliviana para la Democracia Multipartidaria.

RUBIO, D. F. (2012). Financiamiento de los partidos políticos en Argentina: Modelo 2012. Revista Elecciones, ONPE, vol. 11, n. 12, p. 99-112, ene./dic.

SG/OEA; IFE. (2013). El financiamiento de partidos y campañas electorales: situación actual, retos y perspectivas [Documento introductorio de la Sexta Jornada Interamericana Electoral]. Distrito Federal, México: OEA.

SPECK, B.; PFEIFFER, S. (2007). El control ciudadano del financiamiento político. Una guía práctica sobre experiencias y desafíos. Berlín: Transparency International. ISBN 3-9357II-25-5.

ULLOA, F. (2004). Financiamiento político: órganos de control y regímenes de sanciones. En: ZOVATTO, D.; GRINER, S. (ed.). De las normas a las buenas prácticas. El desafío del financiamiento político en América Latina. San José: OEAIDEA. ISBN 0-8270-4723-1.

ZOVATTO, D.; GRINER, S. (ed.) (2004). De las normas a las buenas prácticas. El desafío del financiamiento político en América Latina. San José: OEA-IDEA. ISBN 0-8270-4723-1. 